\title{
Entangled Photon Encoding Using Trapping of Picoseconds Soliton pulse
}

\author{
I. S. Amiri ${ }^{* 1}$, D. Gifany ${ }^{2}$, J. Ali $^{1}$ \\ ${ }^{1}$ Institute of Advanced Photonics Science, Nanotechnology Research Alliance, Universiti \\ Teknologi Malaysia (UTM), 81300 Johor Bahru, Malaysia \\ ${ }^{2}$ Faculty of Engineering and Technology, Multimedia University (MMU), Melaka, Malaysia
}

\begin{abstract}
The microring resonator (MRR) system can be used to trap optical solitons. These types of pulses are used to generate entangled photon required for quantum keys. The required information can be provided via the quantum keys. We simulate localized spatial and temporal soliton pulses to form an optical communication used in wireless systems. The input soliton pulses with peak power of 500 and $550 \mathrm{~mW}$ are used to generate a spectrum of chaotic signals within the nonlinear medium, where the nonlinear refractive index is selected to $n_{2}=2.2 \times 10^{-17} \mathrm{~m}^{2} / \mathrm{W}$. The ultra-short soliton pulse can be trapped within the $3.52 \mathrm{GHz}$ frequency, where the temporal soliton pulse with FWHM of 25 ps could be simulated and used to generate entangled photon pair. The generated entangled photons are input into a wireless router system which is used to transfer them within a network communication system. The router system is used to receive the information and convert it to analog signals at the end of the transmission link, thus data can be sent to the users via a secured optical communication system using MRRs.
\end{abstract}

Keywords: Microring Resonator (MRR), Spatial and Temporal Soliton, Quantum Keys

\section{INTRODUCTION}

Optical communication is an interesting area in Photonics for two decades [1]. It is very attractive especially when it uses quantum cryptography in a network system where it was reported by Amiri et al [2-3]. Quantum keys can form requires information which provides the perfect communication security [4]. Amiri et al. showed that quantum security could be performed via the optical-wired and wireless link [5]. Some research works have shown that some techniques of quantum cryptography are proposed, where the systems of MRR are still complicated [6-8]. Amiri et al proposed a new quantum key distribution rule in which carrier information is encoded on continuous variables of a single photon [9]. In such a way, Alice randomly encodes information on either the central frequency of a narrow band single-photon pulse or the time delay of a broadband single-photon pulse [10]. Liu and Goan studied the entanglement evolution under the influence of non-Markovian thermal environments. The continuous variable systems could be two modes of electromagnetic fields or two nanomechanical oscillators in the quantum domain, where there is no process that can be performed within a single system [11].

To generate a spectrum of light over a broad range [12-13], an optical soliton pulse is recommended as a powerful laser pulse that can be used to generate chaotic filter characteristics when propagating within MRRs [14-19]. Therefore, the capacity of the transmission data can be secured and increased when the chaotic packet switching is employed [20]. In this research, we simulate localized spatial and temporal soliton pulses to form the high capacity and security communication [21-23]. The MRR system is used to trap optical solitons in order to generate entangled photon pair required for quantum keys [24]. Here, generation of the localized ultra-short soliton pulses for continuous variable application is demonstrated [25-27]. The system of quantum key generation can be implemented within the wireless networks [28]. Thus, the links can be set up using the optical soliton, generated by the technique called chaotic filtering scheme in which required signals can be selected and used [29-35]. The device parameters are simulated according to the practical device parameters [36-40], where the results obtained have shown that the entangled photon pair can be performed within the MRR device [41].

\section{THEORETICAL MODELING}

The schematic diagram of the proposed system is as shown in Fig. 1. This system is associated with the practical device. 


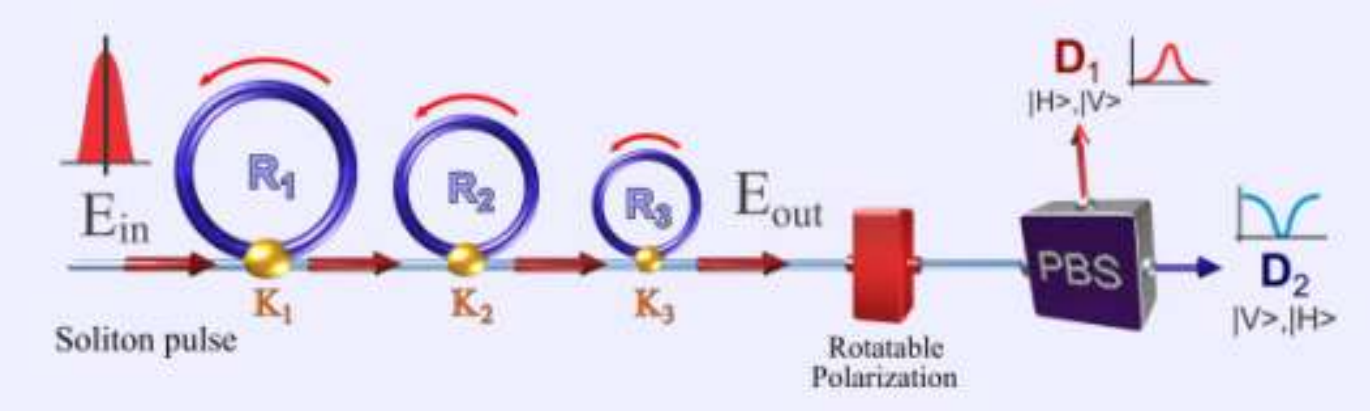

Fig.1: Schematic diagram of a continuous variable quantum key distribution with the different time slot entangled photon encoding. PBS, polarizing beam splitter, Ds, detectors, Rs, ring radii and $\kappa \mathrm{s}$, coupling coefficients.

The soliton pulse is introduced into the proposed system. The input optical field $\left(E_{i n}\right)$ of the bright soliton pulse can be expressed as [42-44],

$$
E_{i n}=A \sec h\left[\frac{T}{T_{0}}\right] \exp \left[\left(\frac{z}{2 L_{D}}\right)-i \omega_{0} t\right]
$$

$A$ and $z$ are the optical field amplitude and propagation distance, respectively [45-47]. $T$ is a soliton pulse propagation time in a frame moving at the group velocity [48], $T=t-\beta_{1} \times z$ [49], where $\beta_{1}$ and $\beta_{2}$ are the coefficients of the linear and second order terms of the Taylor expansion of the propagation constant [50-53]. $L_{D}=T_{0}^{2} /\left|\beta_{2}\right|$ is the dispersion length of the soliton pulse [54-57]. The frequency shift of the soliton is $\omega_{0}$ [58]. This solution describes a pulse that keeps its temporal width invariance as it propagates [59], and thus is called a temporal soliton [60]. When a soliton peak intensity $\left(\left|\beta_{2} / \Gamma T_{0}^{2}\right|\right)$ is given [61], then $T_{o}$ is known [62]. For the soliton pulse in the micro ring device, a balance should be achieved between the dispersion length $\left(L_{\mathrm{D}}\right)$ [63-65] and the nonlinear length $\left(L_{\mathrm{NL}}=\left(1 / \Gamma \phi_{\mathrm{NL}}\right)\right.$ [66-68], where $\Gamma=n_{2} \times k_{0}$ [69], is the length scale over which disperse or nonlinear effects makes the beam becomes wider or narrower [70-71]. For a soliton pulse, there is a balance between dispersion and nonlinear lengths, hence $L_{\mathrm{D}}=L_{\mathrm{NL}}$ [72-75]. When light propagates within the nonlinear medium, the refractive index $(\mathrm{n})$ of light within the medium is given by [76-77]

$$
n=n_{0}+n_{2} I=n_{0}+\left(\frac{n_{2}}{A_{e f f}}\right) P,
$$

where $n_{0}$ and $n_{2}$ are the linear and nonlinear refractive indexes, respectively. $I$ and $P$ are the optical intensity and optical power, respectively [78]. The effective mode core area of the device is given by $A_{\text {eff }}$ [79]. For the MRR, the effective mode core areas range from 0.50 to $0.12 \mu \mathrm{m}^{2}$. The resonant output is can be formed, thus the normalized output of the light field is given by [80-81],

$$
\left|\frac{E_{\text {out }}(t)}{E_{\text {in }}(t)}\right|^{2}=(1-\gamma)\left[1-\frac{\left(1-(1-\gamma) x^{2}\right) \kappa}{(1-x \sqrt{1-\gamma} \sqrt{1-\kappa})^{2}+4 x \sqrt{1-\gamma} \sqrt{1-\kappa} \sin ^{2}\left(\frac{\phi}{2}\right)}\right]
$$

where, the output and input fields in each round-trip are presented by $E_{\text {out }}(\mathrm{t})$ and $E_{\text {in }}$ (t) [82]. Equation (3) indicates that a ring resonator in the particular case is very similar to a Fabry-Perot cavity [83], which has an input and an output mirror with a field reflectivity, $(1-\kappa)$, and a fully reflecting mirror [84]. $\kappa$ is the coupling coefficient [85-87], and $x=\exp (-\alpha L / 2)$ represents a round-trip loss coefficient [88], $\Phi_{0}=k L n_{0}$ [89] and $\Phi_{\mathrm{NL}}=k L n_{2}\left|\mathrm{E}_{\mathrm{in}}\right|^{2} \quad$ [90] are the linear and nonlinear phase shifts, $k=2 \pi / \lambda$ is the wave propagation number in a vacuum [91]. $L$ and $\alpha$ are a waveguide length and linear absorption coefficient, respectively [13]. In this work, the iterative method is introduced to obtain the results as shown in equation (3). 


\section{RESULT AND DISCUSSION}

A soliton pulse with a peak power of $550 \mathrm{~mW}$ is input into the system. The suitable ring parameters are used, for instance, ring radii $R_{1}=10 \mu \mathrm{m}, R_{2}=10 \mu \mathrm{m}$, and $R_{3}=12 \mu \mathrm{m}$. The selected parameters of the system are fixed to $\lambda_{0}=87.5 \mathrm{~mm}, n_{0}=3.34(\mathrm{InGaAsP} / \mathrm{InP}), A_{\text {eff } 1}=0.50, A_{\mathrm{eff} 2}=0.50$ and $A_{\mathrm{eff} 3}=0.25 \mu \mathrm{m}^{2}$ for three microring resonators respectively, $\alpha=0.5 \mathrm{dBmm}^{-1}, \gamma=0.1$. The coupling coefficient $(\kappa)$ of the MRR ranged from 0.97 to 0.998 .

The large bandwidth within the micro ring device can be generated by using a soliton pulse input into the nonlinear MRR shown in Fig. 1, where the required signals perform the secure communication network. The nonlinear refractive index is $n_{2}=2.2 \times 10^{-17} \mathrm{~m}^{2} / \mathrm{W}$. In this case, the wave guided loss used is $0.5 \mathrm{dBmm} \mathrm{mm}^{-1}$. From Fig. 2 , the signal is sliced into a smaller signals spreading over the spectrum. The compress bandwidth is obtained within the ring $R_{2}$. The amplified gain is obtained within a MRR $\left(R_{3}\right)$. Frequency soliton pulse is formed and trapped by using the constant gain condition. The attenuation of the optical power within a MRR is required in order to keep the constant output gain, where the next round input power is attenuated and kept the same level with the $R_{2}$ output.
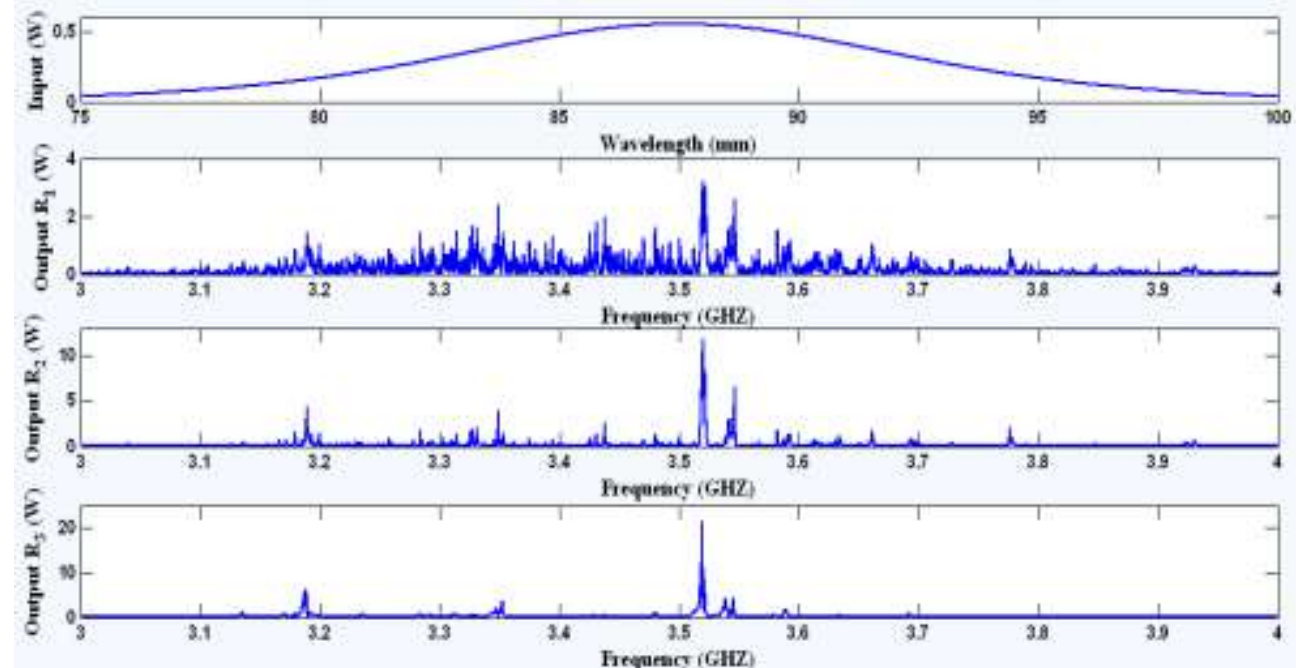

Fig. 2: Results obtained when frequency soliton pulse is localized within a microring device with 20,000 roundtrips, the ring radii are $R_{1}=10 \mu \mathrm{m}, R_{2}=10 \mu \mathrm{m}, R_{3}=12 \mu \mathrm{m}$

Therefore ultra-short of soliton pulse can be trapped within $3.52 \mathrm{GHz}$ frequency as shown in Fig. 2. Similarly, the temporal soliton is obtained as shown in Fig. 3, where a soliton pulse with peak power of $500 \mathrm{~mW}$ is input into the MRRs system. The ring radii $R_{1}=10 \mu \mathrm{m}, R_{2}=5 \mu \mathrm{m}$, and $R_{3}=4 \mathrm{r} \mu \mathrm{m}$. The selected parameters of the system are fixed to $\lambda_{0}=1.55 \mu \mathrm{m}, n_{0}=3.34(\mathrm{InGaAsP} / \mathrm{InP}), A_{\text {eff } 1}=0.50 \mu \mathrm{m}^{2}, A_{\text {eff } 2}=0.25 \mu \mathrm{m}^{2}$ and $A_{\text {eff } 3}=0.12 \mu \mathrm{m}^{2}$ for three microring resonators respectively, $\alpha=0.5 \mathrm{dBmm}^{-1}, \gamma=0.1$. The coupling coefficient of the MRR is fixed to 0.975 . Here, a soliton pulse with FWHM of 25 ps is simulated.
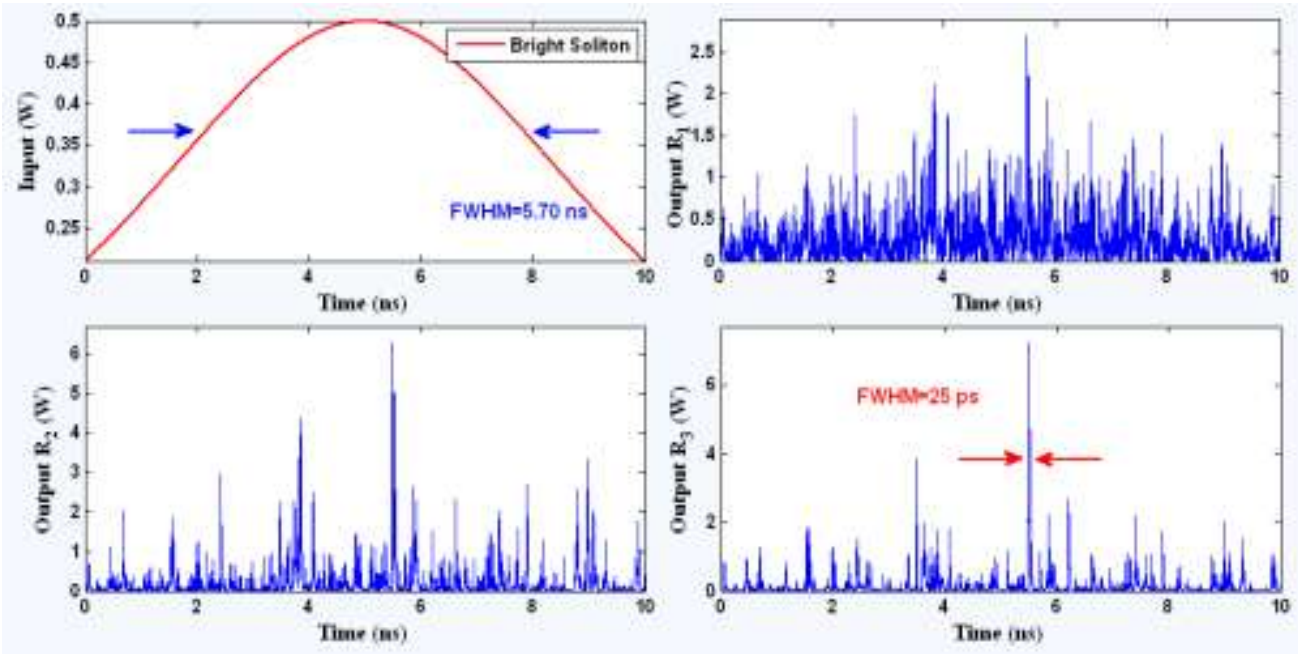

Fig. 3: Results obtained when temporal soliton with FWHM=25 ps is localized within a microring device 
Each pair of the possible polarization entangled photons is formed within different time frames by using the polarization control unit as shown in Fig. 1, which they can be represented by two polarization orientation angles as $\left[0^{\circ}, 90^{\circ}\right]$. They can be formed by using the optical component called the polarization rotatable device and PBS. Here we introduce the technique that is used to generate the qubits. A polarization coupler separates the basic vertical and horizontal polarization states according to an optical switch between the short and long pulses. The following state at time $t_{1}$ is created by Eq. (4).

$$
\left|\Phi>_{\mathrm{p}}=\right| 1, \mathrm{H}>_{\mathrm{s}}\left|1, \mathrm{H}>_{\mathrm{i}}+\right| 2, \mathrm{H}>_{\mathrm{s}} \mid 2, \mathrm{H}>_{\mathrm{i}}
$$

In the expression $|\mathrm{k}, \mathrm{H}\rangle, \mathrm{k}$ is defined as the number of time slots, where it denotes the state of polarization. The subscripts, $s$ and $i$ present the signal and idler states. The two-photon state with $|\mathrm{H}\rangle$ polarization shown by equation (4) is input into the orthogonal polarization-delay circuit. The delay circuit consists of a coupler and the difference between the round-trip times of the MRR is equal to $\Delta t$. The round trip of the ring can be converted into $|\mathrm{V}\rangle$ at the delay circuit output. That is the delay circuits convert

$\mathrm{r}\left|\mathrm{k}, \mathrm{H}>+\mathrm{t}_{2} \exp (\mathrm{i} \Phi)\right| \mathrm{k}+1, \mathrm{~V}>+\mathrm{rt}_{2} \exp \left(\mathrm{i}_{2} \Phi\right)\left|\mathrm{k}+2, \mathrm{H}>+\mathrm{r}_{2} \mathrm{t}_{2} \exp \left(\mathrm{i}_{3} \Phi\right)\right| \mathrm{k}+3, \mathrm{~V}>$

Where $t$ and $r$ is the amplitude transmittances to cross and bar ports in a coupler. Then, the polarized state is given by [92]

$$
\begin{aligned}
& \mid \Phi>=\left[\left|1, \mathrm{H}>_{\mathrm{s}}+\exp \left(\mathrm{i} \Phi_{\mathrm{s}}\right)\right| 2, \mathrm{~V}>_{\mathrm{s}}\right] \times\left[\left|1, \mathrm{H}>_{\mathrm{i}}+\exp \left(\mathrm{i} \Phi_{\mathrm{i}}\right)\right| 2, \mathrm{~V}>_{\mathrm{i}}\right] \\
& +\left[\left|2, \mathrm{H}>_{\mathrm{s}}+\exp \left(\mathrm{i} \Phi_{\mathrm{s}}\right)\right| 3, \mathrm{~V}>_{\mathrm{s}} \times\left[\left|2, \mathrm{H}>_{\mathrm{i}}+\exp \left(\mathrm{i} \Phi_{\mathrm{i}}\right)\right| 2, \mathrm{~V}>_{\mathrm{i}}\right]=\right. \\
& {\left[\left|1, \mathrm{H}>_{\mathrm{s}}\right| 1, \mathrm{H}>_{\mathrm{i}}+\exp \left(\mathrm{i} \Phi_{\mathrm{i}}\right)\left|1, \mathrm{H}>_{\mathrm{s}}\right| 2, \mathrm{~V}>_{\mathrm{i}}\right]+\exp \left(\mathrm{i} \Phi_{\mathrm{s}}\right)\left|2, \mathrm{~V}>_{\mathrm{s}}\right| 1, \mathrm{H}>_{\mathrm{i}}+} \\
& \exp \left[\mathrm{i}\left(\Phi_{\mathrm{s}}+\Phi_{\mathrm{i}}\right)\right]\left|2, \mathrm{~V}>_{\mathrm{s}}\right| 2, \mathrm{~V}>_{\mathrm{i}}+\left|2, \mathrm{H}>_{\mathrm{s}}\right| 2, \mathrm{H}>_{\mathrm{i}}+\exp \left(\mathrm{i} \Phi_{\mathrm{i}}\right)\left|2, \mathrm{H}>_{\mathrm{s}}\right| 3, \mathrm{~V}>_{\mathrm{i}}+ \\
& \exp \left(\mathrm{i} \Phi_{\mathrm{s}}\right)\left|3, \mathrm{~V}>_{\mathrm{s}}\right| 2, \mathrm{H}>_{\mathrm{i}}+\exp \left[\mathrm{i}\left(\Phi_{\mathrm{s}}+\Phi_{\mathrm{i}}\right)\right]\left|3, \mathrm{~V}>_{\mathrm{s}}\right| 3, \mathrm{~V}>_{\mathrm{i}}
\end{aligned}
$$

As a result, we can obtain the following polarization entangled state as

$$
|\Phi>=| 2, \mathrm{H}>_{\mathrm{s}}\left|2, \mathrm{H}>_{\mathrm{i}}+\exp \left[\mathrm{i}\left(\Phi_{\mathrm{s}}+\Phi_{\mathrm{i}}\right)\right]\right| 2, \mathrm{~V}>_{\mathrm{s}} \mid 2, \mathrm{~V}>_{\mathrm{i}}
$$

A wireless router system can be used to transfer generated entangled photons via a wireless access point, and network communication system shown in Fig. 4.

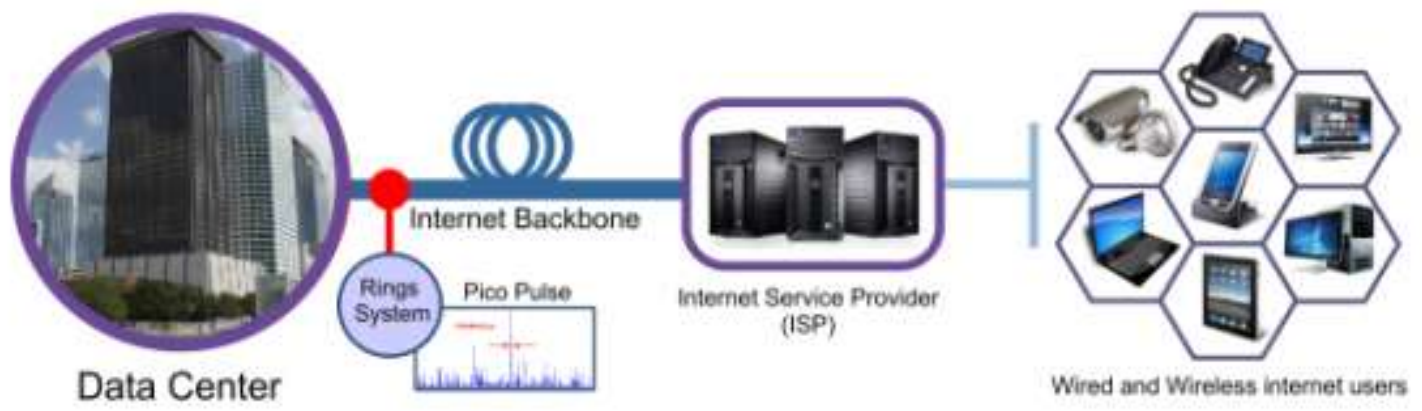

Fig.4: System of entangled photons transmission using a wireless access point system

A wireless access system transmits data to different users via wireless connection [93]. The transmission of information can be sent to the Internet using a physical, wired Ethernet connection. This method also works in reverse, when the router system used to receive information from the Internet, translating it into an analog signal and sending it to the computer's wireless adapter.

\section{CONCLUSION}

An interesting concept can be presented, in which the quantum key is generated by using a remarkably simple system. Proposed system consists of a series of MRRs. Balance between dispersion and nonlinear lengths of the soliton pulse exhibit the self-phase modulation effect. Therefore, light pulse can be trapped, localized coherently within the waveguide. We have shown that a large bandwidth of the arbitrary soliton pulses can be generated and compressed within a micro waveguide. The chaotic signal generation using a soliton pulse propagating within the nonlinear MRR has been presented. A selected light pulse can be localized and used to perform the secure communication network. Localized spatial and temporal soliton pulse can used to generate entangled photon pair that provides quantum keys, applicable for communication networks. We have analyzed 
the entangled photon generated by chaotic signals in the series MRR devices. The classical information and security code can be formed by using the temporal and spatial soliton pulses, respectively, where the transmission of secured data can be implemented via wireless access point system used in optical communication networks.

\section{ACKNOWLEDGEMENTS}

I. S. Amiri would like to thank the Institute of Advanced Photonics Science, Enabling Science \& Nanotechnology Research Alliance, Universiti Teknologi Malaysia (UTM).

\section{REFERENCES}

[1] I. S. Amiri, A. Afroozeh, M. Bahadoran, J. Ali, and P. P. Yupapin, Molecular Transporter System for Qubits Generation, Jurnal Teknologi (Sciences and Engineering), 55, 2012, 155-165.

[2] I. S. Amiri, M. H. Khanmirzaei, M. Kouhnavard, and S. Mitatha, Quantum cryptography via a wavelength router for internet security, Piers Proceeding, Cambridge, 2010.

[3] I. S. Amiri, M. H. Khanmirzaei, M. Kouhnavard, P. P. Yupapin, and J. Ali, Quantum Entanglement using Multi Dark Soliton Correlation for Multivariable Quantum Router, in Quantum Entanglement A. M. Moran, Ed., New York: Nova Science Publisher, 2012.

[4] D. Gifany, I. S. Amiri, M. Ranjbar, and J. Ali, Logic Codes Generation and Transmission Using an Encoding-Decoding System, International Journal of Advances in Engineering \& Technology (IJAET), 5(2), 2013, 37-45

[5] I. S. Amiri, A. Shahidinejad, A. Nikoukar, M. Ranjbar, J. Ali, and P. P. Yupapin, Digital Binary Codes Transmission via TDMA Networks Communication System Using Dark and Bright Optical Soliton, GSTF Journal on Computing (joc), $2(1), 2012$.

[6] A. Afroozeh, I. S. Amiri, M. A. Jalil, M. Kouhnavard, J. Ali, and P. P. Yupapin, Multi Soliton Generation for Enhance Optical Communication, Applied Mechanics and Materials, 83, 2011, 136-140.

[7] I. S. Amiri, A. Nikoukar, and J. Ali, Quantum Information Generation Using Optical Potential Well, presented at the Network Technologies \& Communications (NTC) Conference, Singapore, 2010-2011.

[8] I. S. Amiri, A. Nikoukar, A. Shahidinejad, M. Ranjbar, J. Ali, and P. P. Yupapin, Generation of Quantum Photon Information Using Extremely Narrow Optical Tweezers for Computer Network Communication, GSTF Journal on Computing (joc), 2 (1), 2012.

[9] I. S. Amiri, M. Nikmaram, A. Shahidinejad, and J. Ali, Cryptography Scheme of an Optical Switching System Using Pico/Femto Second Soliton Pulse, International Journal of Advances in Engineering \& Technology (IJAET), 5(1), 2012, 176-184.

[10] M. Kouhnavard, I. S. Amiri, M. Jalil, A. Afroozeh, J. Ali, and P. P. Yupapin, QKD via a quantum wavelength router using spatial soliton, in Enabling Science and Nanotechnology (ESciNano) Conference, Malaysia, 2010, 210-216.

[11] K. L. Liu and H. S. Goan, Non-Markovian entanglement dynamics of quantum continuous variable systems in thermal environments, Physical Review A, 76(2), 2007, 022312.

[12] J. Ali, M. A. Jalil, I. S. Amiri, and P. P. Yupapin, Effects of MRR parameter on the bifurcation behavior, presented at the Nanotech Malaysia, International Conference on Enabling Science \& Technology, KLCC, Kuala Lumpur, Malaysia 2010.

[13] C. Teeka, S. Songmuang, R. Jomtarak, P. P. Yupapin, M. A. Jalil, I. S. Amiri, and J. Ali, ASK to PSK Generation based on Nonlinear Microring Resonators Coupled to One MZI Arm, in International Conference on Enabling Science and Nanotechnology, EsciNano, 2011, 221-223.

[14] A. Afroozeh, I. S. Amiri, M. Kouhnavard, M. Bahadoran, M. A. Jalil, J. Ali, and P. P. Yupapin, Dark and Bright Soliton trapping using NMRR, presented at the International Conference on Experimental Mechanics (ICEM), Kuala Lumpur, Malaysia, 2010.

[15] J. Ali, A. Afroozeh, I. Amiri, M. Jalil, and P. Yupapin, Wide and narrow signal generation using chaotic wave, presented at the Nanotech Malaysia, International Conference on Enabling Science \& Technology, Kuala Lumpur, Malaysia, 2010.

[16] J. Ali, I. S. Amiri, M. A. Jalil, A. Afroozeh, M. Kouhnavard, and P. P. Yupapin, Multi-soliton generation and storage for nano optical network using nano ring resonators, presented at the ICAMN, International Conference, Prince Hotel, Kuala Lumpur, Malaysia, 2010.

[17] I. S. Amiri, A. Afroozeh, I. N. Nawi, M. A. Jalil, A. Mohamad, J. Ali, and P. P. Yupapin, Dark Soliton Array for communication security, Procedia Engineering, 8, 2011, 417-422.

[18] I. S. Amiri, A. Nikoukar, A. Shahidinejad, J. Ali, and P. Yupapin, Generation of discrete frequency and wavelength for secured computer networks system using integrated ring resonators, in Computer and Communication Engineering (ICCCE) Conference, Malaysia, 2012, 775-778.

[19] A. A. Shojaei and I. S. Amiri, Soliton for Radio wave generation, presented at the International Conference for Nanomaterials Synthesis and Characterization (INSC), Kuala Lumpur, Malaysia, 2011.

[20] I. S. Amiri, R. Ahsan, A. Shahidinejad, J. Ali, and P. P. Yupapin, Characterisation of bifurcation and chaos in silicon microring resonator, IET Communications, 6(16), 2012, 2671-2675.

[21] J. Ali, I. S. Amiri, M. A. Jalil, M. Hamdi, F. K. Mohamad, N. J. Ridha, and P. P. Yupapin, Trapping spatial and temporal soliton system for entangled photon encoding, presented at the Nanotech Malaysia, International Conference on Enabling Science \& Technology, Kuala Lumpur, Malaysia, 2010.

[22] J. Ali, M. Kouhnavard, I. S. Amiri, A. Afroozeh, M. A. Jalil, I. Naim, and P. P. Yupapin, Localization of soliton pulse using nanowaveguide, presented at the ICAMN, International Conference, Prince Hotel, Kuala Lumpur, Malaysia, 2010.

[23] J. Ali, K. Kulsirirat, W. Techithdeera, M. A. Jalil, I. S. Amiri, I. Naim, and P. P. Yupapin, Temporal dark soliton behavior within multi-ring resonators, presented at the Nanotech Malaysia, International Conference on Enabling Science \& Technology, Malaysia, 2010.

[24] I. S. Amiri, A. Nikoukar, G. Vahedi, A. Shojaei, J. Ali, and P. Yupapin, Frequency-Wavelength Trapping by Integrated Ring Resonators For Secured Network and Communication Systems, International Journal of Engineering Research \& Technology (IJERT), 1(5), 2012.

[25] I. S. Amiri, A. Nikoukar, J. Ali, and P. P. Yupapin, Ultra-Short of Pico and Femtosecond Soliton Laser Pulse Using Microring Resonator for Cancer Cells Treatment, Quantum Matter, 1(2), 2012, 159-165.

[26] S. Saktioto, M. Hamdi, I. S. Amiri, and J. Ali, Transition of diatomic molecular oscillator process in THz region, presented at the International Conference on Experimental Mechanics (ICEM), Legend Hotel, Kuala Lumpur, Malaysia, 2010.

[27] P. P. Yupapin, M. A. Jalil, I. S. Amiri, I. Naim, and J. Ali, New Communication Bands Generated by Using a Soliton Pulse within a Resonator System, Circuits and Systems, 1(2), 2010, 71-75.

[28] A. Nikoukar, I. S. Amiri, and J. Ali, Secured Binary Codes Generation for Computer Network Communication, presented at the Network Technologies \& Communications (NTC) Conference, Singapore, 2010-2011. 
[29] N. J. Ridha, F. K. Mohamad, I. S. Amiri, Saktioto, J. Ali, and P. P. Yupapin, Soliton Signals and The Effect of Coupling Coefficient in MRR Systems, presented at the International Conference on Experimental Mechanics (ICEM), Kuala Lumpur, Malaysia, 2010.

[30] I. S. Amiri, A. Afroozeh, and M. Bahadoran, Simulation and Analysis of Multisoliton Generation Using a PANDA Ring Resonator System, Chinese Physics Letters, 28, 2011, 104205.

[31] J. Ali, I. Amiri, A. Jalil, A. Kouhnavard, B. Mitatha, and P. Yupapin, Quantum internet via a quantum processor, presented at the International Conference on Photonics (ICP), Langkawi, Malaysia 2010.

[32] A. Afroozeh, I. S. Amiri, M. Kouhnavard, M. Jalil, J. Ali, and P. Yupapin, Optical dark and bright soliton generation and amplification, in Enabling Science and Nanotechnology (ESciNano) Conference, Malaysia, 2010, 259-263.

[33] M. Kouhnavard, A. Afroozeh, I. S. Amiri, M. A. Jalil, J. Ali, and P. P. Yupapin, New system of Chaotic Signal Generation Using MRR, presented at the International Conference on Experimental Mechanics (ICEM), Kuala Lumpur, Malaysia, 2010.

[34] A. Shahidinejad, A. Nikoukar, I. S. Amiri, M. Ranjbar, A. Shojaei, J. Ali, and P. Yupapin, Network system engineering by controlling the chaotic signals using silicon micro ring resonator, in Computer and Communication Engineering (ICCCE) Conference, Malaysia, 2012, 765-769.

[35] J. Ali, M. A. Jalil, I. S. Amiri, and P. P. Yupapin, MRR quantum dense coding, presented at the Nanotech Malaysia, International Conference on Enabling Science \& Technology, KLCC, Kuala Lumpur, Malaysia 2010.

[36] A. Afroozeh, I. S. Amiri, A. Samavati, J. Ali, and P. Yupapin, THz frequency generation using MRRs for THz imaging, in Enabling Science and Nanotechnology (ESciNano) Conference, Malaysia, 2012, 1-2.

[37] J. Ali, I. S. Amiri, M. A. Jalil, M. Hamdi, F. K. Mohamad, N. J. Ridha, and P. P. Yupapin, Proposed molecule transporter system for qubits generation, presented at the Nanotech Malaysia, International Conference on Enabling Science \& Technology, Malaysia 2010.

[38] J. Ali, M. A. Jalil, I. S. Amiri, and P. P. Yupapin, Fast and slow lights via an add/drop device, presented at the ICEM Conference, Legend Hotel, Kuala Lumpur, Malaysia, 2010.

[39] I. S. Amiri, J. Ali, and P. P. Yupapin, Enhancement of FSR and Finesse Using Add/Drop Filter and PANDA Ring Resonator Systems, International Journal of Modern Physics B, 26(04), 2012.

[40] I. S. Amiri, G. Vahedi, A. Nikoukar, A. Shojaei, J. Ali, and P. Yupapin, Decimal Convertor Application for Optical Wireless Communication by Generating of Dark and Bright Signals of soliton, International Journal of Engineering Research \& Technology (IJERT), 1(5), 2012.

[41] J. Ali, M. Kouhnavard, M. A. Jalil, and I. S. Amiri, Quantum signal processing via an optical potential well, presented at the Nanotech Malaysia, International Conference on Enabling Science \& Technology, Kuala Lumpur, Malaysia 2010.

[42] J. Ali, A. Afroozeh, I. S. Amiri, M. A. Jalil, and P. P. Yupapin, Dark and Bright Soliton trapping using NMRR, presented at the ICEM Conference, Legend Hotel, Kuala Lumpur, Malaysia, 2010.

[43] J. Ali, M. A. Jalil, I. S. Amiri, and P. P. Yupapin, Dark-bright solitons conversion system via an add/drop filter for signal security application, presented at the ICEM Conference, Legend Hotel, Kuala Lumpur, Malaysia, 2010.

[44] J. Ali, M. Kouhnavard, I. S. Amiri, M. A. Jalil, A. Afroozeh, and P. P. Yupapin, Security confirmation using temporal dark and bright soliton via nonlinear system, presented at the ICAMN, International Conference, Prince Hotel, Kuala Lumpur, Malaysia, 2010.

[45] C. Tanaram, C. Teeka, R. Jomtarak, P. P. Yupapin, M. A. Jalil, I. S. Amiri, and J. Ali, ASK-to-PSK generation based on nonlinear microring resonators coupled to one MZI arm, Procedia Engineering, 8, 2011, 432-435.

[46] F. K. Mohamad, N. J. Ridha, I. S. Amiri, J. A. Saktioto, and P. P. Yupapin, Effect of Center Wavelength on MRR Performance, presented at the International Conference on Experimental Mechanics (ICEM), Kuala Lumpur, Malaysia, 2010.

[47] I. S. Amiri, K. Raman, A. Afroozeh, M. A. Jalil, I. N. Nawi, J. Ali, and P. P. Yupapin, Generation of DSA for security application, Procedia Engineering, 8, 2011, 360-365.

[48] A. A. Shojaei and I. S. Amiri, DSA for Secured Optical Communication, presented at the International Conference for Nanomaterials Synthesis and Characterization (INSC), Kuala Lumpur, Malaysia, 2011.

[49] A. Afroozeh, M. Bahadoran, I. S. Amiri, A. R. Samavati, J. Ali, and P. P. Yupapin, Fast Light Generation Using GaAlAs/GaAs Waveguide, Jurnal Teknologi (Sciences and Engineering), 57, 2012, 17-23.

[50] A. Afroozeh, I. S. Amiri, M. Kouhnavard, M. Bahadoran, M. A. Jalil, J. Ali, and P. P. Yupapin, Optical Memory Time using Multi Bright Soliton, presented at the International Conference on Experimental Mechanics (ICEM), Kuala Lumpur, Malaysia, 2010.

[51] J. Ali, A. Afroozeh, M. Hamdi, I. S. Amiri, M. A. Jalil, M. Kouhnavard, and P. Yupapin, Optical bistability behaviour in a doublecoupler ring resonator, presented at the ICAMN, International Conference, Prince Hotel, Kuala Lumpur, Malaysia, 2010.

[52] J. Ali, M. A. Jalil, I. S. Amiri, A. Afroozeh, M. Kouhnavard, and P. P. Yupapin, Generation of tunable dynamic tweezers using dark-bright collision, presented at the ICAMN, International Conference, Prince Hotel, Kuala Lumpur, Malaysia, 2010.

[53] I. S. Amiri, M. A. Jalil, A. Afroozeh, M. Kouhnavard, J. Ali, and P. P. Yupapin, Controlling Center Wavelength and Free Spectrum Range by MRR Radii, in Faculty of Science Postgraduate Conference (FSPGC), Universiti Teknologi Malaysia, 2010.

[54] J. Ali, A. Afroozeh, I. S. Amiri, M. A. Jalil, M. Kouhnavard, and P. P. Yupapin, Generation of continuous optical spectrum by soliton into a nano-waveguide, presented at the ICAMN, International Conference, Prince Hotel, Kuala Lumpur, Malaysia, 2010.

[55] J. Ali, I. S. Amiri, M. A. Jalil, F. K. Mohamad, and P. P. Yupapin, Optical dark and bright soliton generation and amplification, presented at the Nanotech Malaysia, International Conference on Enabling Science \& Technology, KLCC, Kuala Lumpur, Malaysia, 2010.

[56] I. S. Amiri, A. Afroozeh, M. Bahadoran, J. Ali, and P. P. Yupapin, Up and Down Link of Soliton for Network Communication, presented at the National Science Postgraduate Conference, NSPC, Malaysia, 2011.

[57] M. Kouhnavard, A. Afroozeh, M. A. Jalil, I. S. Amiri, J. Ali, and P. P. Yupapin, Soliton Signals and the Effect of Coupling Coefficient in MRR Systems, in Faculty of Science Postgraduate Conference (FSPGC), Universiti Teknologi Malaysia, 2010.

[58] J. Ali, M. Jalil, I. Amiri, A. Afroozeh, M. Kouhnavard, I. Naim, and P. Yupapin, Multi-wavelength narrow pulse generation using MRR, presented at the ICAMN, International Conference, Prince Hotel, Kuala Lumpur, Malaysia, 2010.

[59] J. Ali, H. Nur, S. Lee, A. Afroozeh, I. Amiri, M. Jalil, A. Mohamad, and P. Yupapin, Short and millimeter optical soliton generation using dark and bright soliton, presented at the AMN-APLOC International Conference, Wuhan, China, 2010

[60] J. Ali, I. Amiri, A. Afroozeh, M. Kouhnavard, M. Jalil, and P. Yupapin, Simultaneous dark and bright soliton trapping using nonlinear MRR and NRR, presented at the ICAMN, International Conference, Malaysia, 2010.

[61] J. Ali, A. Mohamad, I. Nawi, I. Amiri, M. Jalil, A. Afroozeh, and P. Yupapin, Stopping a dark soliton pulse within an NNRR, presented at the AMN-APLOC International Conference, Wuhan, China 2010.

[62] I. S. Amiri, S. Babakhani, G. Vahedi, J. Ali, and P. Yupapin, Dark-Bright Solitons Conversion System for Secured and Long Distance Optical Communication, IOSR Journal of Applied Physics (IOSR-JAP), 2(1), 2012, 43-48. 
[63] A. Afroozeh, I. S. Amiri, J. Ali, and P. P. Yupapin, Determination Of Fwhm For Solition Trapping, Jurnal Teknologi (Sciences and Engineering), 55, 2012, 77-83.

[64] J. Ali, I. S. Amiri, M. A. Jalil, A. Afroozeh, M. Kouhnavard, and P. Yupapin, Novel system of fast and slow light generation using micro and nano ring resonators, presented at the ICAMN, International Conference, Prince Hotel, Kuala Lumpur, Malaysia, 2010.

[65] I. S. Amiri, M. Ranjbar, A. Nikoukar, A. Shahidinejad, J. Ali, and P. Yupapin, Multi optical Soliton generated by PANDA ring resonator for secure network communication, in Computer and Communication Engineering (ICCCE) Conference, Malaysia, 2012, 760-764.

[66] J. Ali, I. Amiri, M. Jalil, M. Kouhnavard, A. Afroozeh, I. Naim, and P. Yupapin, Narrow UV pulse generation using MRR and NRR system, presented at the ICAMN, International Conference, Prince Hotel, Kuala Lumpur, Malaysia, 2010.

[67] I. S. Amiri, M. A. Jalil, F. K. Mohamad, N. J. Ridha, J. Ali, and P. P. Yupapin, Storage of Atom/Molecules/Photon using Optical Potential Wells, presented at the International Conference on Experimental Mechanics (ICEM), Kuala Lumpur, Malaysia, 2010.

[68] A. Nikoukar, I. S. Amiri, A. Shahidinejad, A. Shojaei, J. Ali, and P. Yupapin, MRR quantum dense coding for optical wireless communication system using decimal convertor, in Computer and Communication Engineering (ICCCE) Conference, Malaysia, 2012, 770-774.

[69] J. Ali, M. Kouhnavard, A. Afroozeh, I. S. Amiri, M. A. Jalil, and P. P. Yupapin, Optical bistability in a FORR, presented at the ICEM Conference, Legend Hotel, Kuala Lumpur, Malaysia, 2010.

[70] J. Ali, M. Aziz, I. Amiri, M. Jalil, A. Afroozeh, I. Nawi, and P. Yupapin, Soliton wavelength division in MRR and NRR Systems, presented at the AMN-APLOC International Conference, Wuhan, China 2010.

[71] I. Amiri, J. Ali, and P. Yupapin, Security Enhancement of the Optical Signal Communication using Binary Codes Generated by Optical Tweezers, Chinese Journal of Physics, 2013.

[72] A. Afroozeh, M. Bahadoran, I. S. Amiri, A. R. Samavati, J. Ali, and P. P. Yupapin, Fast Light Generation Using Microring Resonators for Optical Communication, presented at the National Science Postgraduate Conference NSPC, Universiti Teknologi Malaysia, 2011.

[73] J. Ali, K. Raman, A. Afroozeh, I. S. Amiri, M. A. Jalil, I. N. Nawi, and P. P. Yupapin, Generation of DSA for security application, presented at the 2nd International Science, Social Science, Engineering Energy Conference (I-SEEC), Nakhonphanom, Thailand, 2010 .

[74] J. Ali, K. Raman, M. Kouhnavard, I. S. Amiri, M. A. Jalil, A. Afroozeh, and P. P. Yupapin, Dark soliton array for communication security, presented at the AMN-APLOC International Conference, Wuhan, China, 2011.

[75] M. A. Jalil, I. S. Amiri, M. Kouhnavard, A. Afroozeh, J. Ali, and P. P. Yupapin, Finesse Improvements of Light Pulses within MRR System, in Faculty of Science Postgraduate Conference (FSPGC), Universiti Teknologi Malaysia, 2010.

[76] J. Ali, A. Afroozeh, I. S. Amiri, M. Hamdi, M. Jalil, M. Kouhnavard, and P. Yupapin, Entangled photon generation and recovery via MRR, presented at the ICAMN, International Conference, Prince Hotel, Kuala Lumpur, Malaysia, 2010.

[77] I. S. Amiri, A. Afroozeh, J. Ali, and P. P. Yupapin, Generation Of Quantum Codes Using Up And Down Link Optical Solition, Jurnal Teknologi (Sciences and Engineering), 55, 2012, 97-106.

[78] J. Ali, S. Saktioto, M. Hamdi, and I. S. Amiri, Dynamic silicon dioxide fiber coupling polarized by voltage breakdown, presented at the Nanotech Malaysia, International Conference on Enabling Science \& Technology, KLCC, Kuala Lumpur, Malaysia, 2010.

[79] M. A. Jalil, I. S. Amiri, C. Teeka, J. Ali, and P. P. Yupapin, All-optical Logic XOR/XNOR Gate Operation using Microring and Nanoring Resonators, Global Journal of Physics Express, 1(1), 2011, 15-22.

[80] J. Ali, M. Roslan, M. Jalil, I. Amiri, A. Afroozeh, I. Nawi, and P. Yupapin, DWDM enhancement in micro and nano waveguide, presented at the AMN-APLOC International Conference, Wuhan, China, 2010.

[81] M. Bahadoran, I. S. Amiri, A. Afroozeh, J. Ali, and P. P. Yupapin, Analytical Vernier Effect for Silicon Panda Ring Resonator, presented at the National Science Postgraduate Conference, NSPC, Universiti Teknologi Malaysia, 2011.

[82] F. K. Mohamad, N. J. Ridha, I. S. Amiri, J. A. Saktioto, and P. P. Yupapin, Finesse Improvements of Light Pulses within MRR System, presented at the International Conference on Experimental Mechanics (ICEM), Kuala Lumpur, Malaysia, 2010.

[83] N. Suwanpayak, S. Songmuang, M. A. Jalil, I. S. Amiri, I. Naim, J. Ali, and P. P. Yupapin, Tunable and storage potential wells using microring resonator system for bio-cell trapping and delivery, in Enabling Science and Nanotechnology (ESciNano) Conference, 2010, 289-291.

[84] I. S. Amiri, A. Shahidinejad, A. Nikoukar, J. Ali, and P. Yupapin, A Study oF Dynamic Optical Tweezers Generation For Communication Networks, International Journal of Advances in Engineering \& Technology (IJAET), 4(2), 2012, 38-45.

[85] M. Imran, R. A. Rahman, and I. S. Amiri, Fabrication of Diffractive Optical Element using Direct Writing CO2 Laser Irradiation, in Faculty of Science Postgraduate Conference (FSPGC), Universiti Teknologi Malaysia, 2010.

[86] S. Saktioto, S. Daud, J. Ali, M. A. Jalil, I. S. Amiri, and P. P. Yupapin, FBG simulation and experimental temperature measurement, presented at the ICEM Conference, Legend Hotel, Kuala Lumpur, Malaysia, 2010.

[87] S. Saktioto, S. Daud, M. A. Jalil, I. S. Amiri, and P. P. Yupapin, FBG sensing system for outdoor temperature measurement, presented at the ICEM Conference, Legend Hotel, Kuala Lumpur, Malaysia, 2010.

[88] I. S. Amiri, M. A. Jalil, F. K. Mohamad, N. J. Ridha, J. Ali, and P. P. Yupapin, Storage of Optical Soliton Wavelengths Using NMRR, presented at the International Conference on Experimental Mechanics (ICEM), Kuala Lumpur, Malaysia, 2010.

[89] A. Afroozeh, M. Kouhnavard, I. S. Amiri, M. A. Jalil, J. Ali, and P. P. Yupapin, Effect of Center Wavelength on MRR Performance, in Faculty of Science Postgraduate Conference (FSPGC), Universiti Teknologi Malaysia, 2010.

[90] N. J. Ridha, F. K. Mohamad, I. S. Amiri, Saktioto, J. Ali, and P. P. Yupapin, Controlling Center Wavelength and Free Spectrum Range by MRR Radii, presented at the International Conference on Experimental Mechanics (ICEM), Kuala Lumpur, Malaysia, 2010 .

[91] S. Saktioto, J. Ali, M. Hamdi, and I. Amiri, Calculation and prediction of blood plasma glucose concentration, presented at the ICAMN, International Conference, Prince Hotel, Kuala Lumpur, Malaysia, 2010.

[92] I. S. Amiri, G. Vahedi, A. Shojaei, A. Nikoukar, J. Ali, and P. P. Yupapin, Secured Transportation of Quantum Codes Using Integrated PANDA-Add/drop and TDMA Systems, International Journal of Engineering Research \& Technology (IJERT), 1(5), 2012 .

[93] A. Afroozeh, I. S. Amiri, M. Bahadoran, J. Ali, and P. P. Yupapin, Simulation of Soliton Amplification in Micro Ring Resonator for Optical Communication, Jurnal Teknologi (Sciences and Engineering), 55, 2012, 271-277. 